\title{
Effect of smoke and non-smoke tobacco on nitric oxide levels in diabetic patients
}

\author{
Liza Das, Arvind Mishra, Abbas Ali Mahdi ${ }^{1}$, Amit Shankar Singh \\ Departments of Medicine and 'Biochemistry, King George's Medical University, Lucknow, Uttar Pradesh, India
}

\section{ABSTRACT}

Objective: Diabetes mellitus confers an increased cardiometabolic risk in affected individuals. Several mechanisms underlie this equation, but endothelial dysfunction has been implicated as the final common pathway by several studies. Endogenous nitric oxide (NO) is one of the principal molecules mediating normal endothelial vasodilation. This study was aimed at ascertaining the effects of smoke and non-smoke tobacco, both of which are commonly used by Indians, on the serum NO levels. Materials and Methods: A total of 208 type 2 diabetic patients attending the diabetes clinic were enrolled in this study. Data on age, gender, smoking, and tobacco chewing were collected, and the serum levels of NO determined using nitrate reductase and Griess Reagent which converts nitrite to a deep purple azo compound. The amount of the azochromophore accurately reflected the amount of NO in the samples. Results: The mean value of serum NO in smokers was $54.92 \mu \mathrm{mol} / \mathrm{L}$, as compared to 60.60 $\mu \mathrm{mol} / \mathrm{L}$ in non-smokers. The mean value of serum NO in tobacco chewers was $57.32 \mu \mathrm{mol} / \mathrm{L}$ and in tobacco non-chewers was $60.61 \mu \mathrm{mol} / \mathrm{L}$. In this study, a near-significant association was found between the low serum levels of NO in smokers as compared to nonsmokers. But there was no significant association of serum NO levels in tobacco chewers and non-tobacco chewers. Conclusion: In this study, the difference in effects of different forms of nicotine usage on the NO levels was assessed, as it provides an insight into the mechanism of the effects of oral versus inhaled forms of nicotine use. In conclusion, new facts have been elucidated in this study, and to the best of our knowledge, this is the first comparison of smoke and nonsmoke tobacco in relation to the serum levels of NO for estimating the burden of vascular risk with various forms of tobacco use in diabetes.

Key words: Addiction, diabetes, nicotine, nitric oxide, tobacco

\section{INTRODUCTION}

Address for Correspondence: Dr. Amit S. Singh, Department of Medicine, King George's Medical University, Lucknow,

Uttar Pradesh, India.

E-mail: amitkgmumedicine@gmail.com

\begin{tabular}{|l|}
\hline Access this article online \\
Website: \\
www.intern-med.com \\
\hline DOI: \\
10.4103/2224-4018.129503 \\
\hline Quick Response Code: \\
\hline
\end{tabular}

Cigarette smoking is associated with an increased risk of cardiovascular diseases through increased hypertension and platelet aggregation. ${ }^{[1-3]}$ Both these symptoms may be caused by decreased endogenous nitric oxide (NO) formation. NO has been shown to be an important regulator of blood flow and smooth muscle relaxation. ${ }^{[4,5]}$ It is a factor that is essential for normal physiological regulation of blood flow and nutrient delivery to tissues. Its absence or deficient production is considered to be one of the earliest indicators of disease progression and development of various vascular morbidity patterns. The endogenous and exogenous factors that influence its levels in the body and their possible effects have been a matter of debate since the discovery of this molecule. The search got more intensified when its association with type 2 diabetes mellitus (DM) and its complications was revealed..$^{[-9]}$

Always there has been a quest to know the mechanism of how nicotine, an important component of cigarette smoke, acts in the body, culminating into such risk factors. There are studies indicating that tobacco in smoke form is more hazardous as a vascular risk factor than in other forms. In this study, we tried to evaluate the effect of smoke and non-smoke tobacco use on the serum levels of $\mathrm{NO}$ in diabetic patients to establish the link between the deleterious effects of different forms of nicotine 
use and one of the most important markers of diabetic endovascular injuries, i.e. NO.

\section{MATERIALS AND METHODS}

\section{Study population}

The study was conducted in 208 consecutive diabetic patients who visited the Medicine Department of King George's Medical University over a period of 1 year from August 2012 to August 2013. Informed consent was taken from all the patients or their relatives before inclusion in this observational study.

\section{Clinical evaluation of study population}

Patients of DM attending the outpatient wards and admitted in our medical university wards were enrolled in this cross-sectional observational study and subjected to our criteria of inclusion. Detailed histories regarding past illness, treatment, and family history of DM were taken. In this study, we included all type 2 diabetic patients attending our hospital, irrespective of the presenting complaints, and who had known history of diabetes diagnosed earlier by qualified doctors or who had documents pertaining to their diabetic history. We excluded severely ill patients, patients in shock, and patients of diabetic ketoacidosis.

\section{Evaluation of smoke and non-smoke tobacco usage in diabetes patients}

Current smokers were defined as persons who reported smoking at least 100 cigarettes during their lifetime or who, at the time of interview, reported smoking every day or most days of the week. Chewing tobacco is a type of smokeless tobacco product consumed by placing a portion of the tobacco between the cheek and the gum or the upper lip teeth and chewing to release the flavor and nicotine. Tobacco chewers were considered to be patients who were in habit of tobacco chewing in the form of plugs, twists, or wads, typically sold in pouches of loose tobacco leaves fashioned into long strands or twists. We considered all those patients who were using this form of tobacco for more than 6 months regularly as tobacco chewers.

\section{Assessment of serum NO levels in diabetic patients}

After an overnight fast, blood was taken from the antecubital vein following universal precautions and was equally distributed in $0.5 \mathrm{M}$ ethylenediaminetetraacetic acid (EDTA; pH 8.0) and plain vials for enzyme assays and biochemical estimations, respectively. The blood in the plain vials was allowed to clot in the aliquot at room temperature for about an hour and then immediately centrifuged at $3000 \mathrm{rpm}$ for $10 \mathrm{~min}$ to separate the serum. Serum NO levels were assayed using a colorimetric kit that provides a convenient measurement of the stable decomposition product, total nitrate/nitrite, in the serum by a simple two-step process. The first step was to convert nitrate to nitrite utilizing nitrate reductase. The second step used Griess Reagent to convert nitrite to a deep purple azo compound. The amount of the azochromophore accurately reflected the amount of $\mathrm{NO}$ in the samples.

\section{Statistical analysis}

The results were presented in mean \pm standard deviation (SD) and percentage. Chi-square test was used to compare the dichotomous/categorical variables. The unpaired $t$-test was used to compare two means. One-way analysis of variance was used to detect significant differences in the mean values. $P$-values $<0.05$ were considered as significant. All the analyses were carried out using Statistical Program for Social Sciences (SPSS) version 15.0.

\section{RESULTS}

\section{Demographic profile of diabetes patients}

This study was carried out in a total of 208 diabetic patients who attended our medical university. Patients' age ranged from 41 to 87 years, with a mean age of $64.8 \pm 9.8$ years. Majority of the patients were males $(56.7 \%)$. A total of $19.2 \%$ were smokers and $18.3 \%$ were tobacco chewers [Table 1]. It was noticed that there were 19 patients who were both smokers and tobacco chewers.

\section{Association of NO levels with gender in diabetes patients}

The mean values of $\mathrm{NO}$ in diabetic males and females were $59.95 \mu \mathrm{mol} / \mathrm{L}$ and $58.92 \mu \mathrm{mol} / \mathrm{L}$, respectively. There was no significant association found between the serum NO levels and gender $(P>0.05)$ [Table 2].

Table 1: Demographic profile and general characteristics of patients $(N=208)$

\begin{tabular}{lc}
\hline Characteristic & Statistic (\%) \\
\hline $\begin{array}{l}\text { Mean age } \pm \text { SD (range), (years) } \\
\text { Gender }\end{array}$ & $64.8 \pm 9.8(41-87)$ \\
Male & $118(56.7)$ \\
Female & $90(43.3)$ \\
Addictions & \\
$\quad$ Smokers & $40(19.2)$ \\
Tobacco chewers & $38(18.3)$ \\
\hline
\end{tabular}

Table 2: Association of NO levels with gender

\begin{tabular}{lccc}
\hline Gender & \multicolumn{3}{c}{ Total $(\boldsymbol{N}=\mathbf{2 0 8})$} \\
\cline { 2 - 4 } & $\boldsymbol{n}$ & $\begin{array}{c}\text { Mean nitric oxide } \\
\text { in serum }(\boldsymbol{\mu m o l} / \mathrm{L})\end{array}$ & SD \\
\hline Male & 118 & 59.95 & 17.21 \\
Female & 90 & 58.92 & 18.39 \\
$t$ & 0.415 & & \\
$P$ value & 0.679 & & \\
\hline
\end{tabular}




\section{Association of serum NO levels with age in diabetes patients}

The mean age of patients was $64.8 \pm 9.8$ (41-87) years, and when we distributed the patients according to increasing age in different groups, we found no significant association between NO and increasing age of the patients $(P>0.05)$ [Table 3].

\section{Association between serum NO levels with smoke and non-smoke tobacco usage in diabetes patients}

The mean value of serum NO in smokers was 54.92 $\mu \mathrm{mol} / \mathrm{L}$, as compared to $60.60 \mu \mathrm{mol} / \mathrm{L}$ in non-smokers. The mean value of serum $\mathrm{NO}$ in tobacco chewers was $57.32 \mu \mathrm{mol} / \mathrm{L}$ and in tobacco non-chewers was $60.61 \mu \mathrm{mol} / \mathrm{L}$. In the study, a near-significant association was found between the low serum levels in smokers as compared to non-smokers. But there was no significant association in the serum NO levels of tobacco chewers and non-tobacco chewers [Table 4][Figure 1].

There was overlap of both smoking and tobacco usage in 19 patients, but we did not exclude those from the study as we intended to find the relation between smokers and non-smokers irrespective of other factors, in order to know the effect of smoking on serum NO levels in those patients. Similarly, we intended to know the effect of tobacco chewing only on serum NO levels in respect to non-tobacco chewers.

\section{DISCUSSION}

The study was conducted in diabetic patients to assess the additive effects of tobacco in vascular dysfunction. What we found was interesting, as we could assign the role of smoke tobacco in vascular dysfunction, though not definitely, as there was only a near association in the results. As we know, cigarette smoke has been implicated as a major risk factor in chronic obstructive pulmonary disease, chronic hypoxic cor pulmonale,

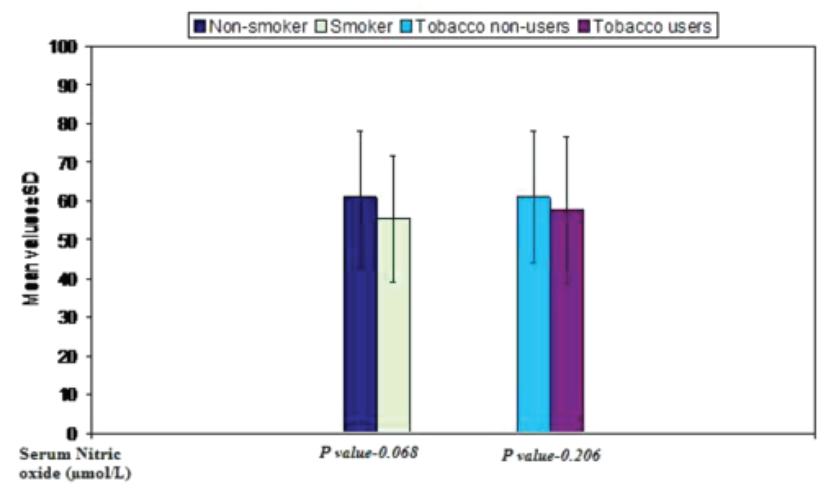

Figure 1: Association of serum nitric oxide levels with smoke and non-smoke tobacco users atherosclerosis, and various other related cardiovascular dysfunctions. ${ }^{[10]}$ The mechanism for the increased risk of vascular dysfunction is not well understood, but it is presumed to be due to the absorption of tobacco smoke constituents that affect endothelial cell function. ${ }^{[1]}$ Cigarette smoke is a complex medium containing approximately 4000 different constituents distributed in gas and particulate phases. ${ }^{[12]} \mathrm{It}$ contains a variety of oxidants, including nitrogen oxides, hydrogen peroxide, hydrogen cyanide, and acrolein, which are capable of affecting endothelial nitric oxide synthase (eNOS) expression and/or activity. ${ }^{[12]}$

NO is a free radical gas, and acts a powerful regulator of circulation by being an endogenous vasodilator. It plays an important role as a signal molecule, besides being effective as an important neurotransmitter, a pain mediator, and an agent implicated in wound healing and tissue repair. ${ }^{[13]}$ Since the discovery of $\mathrm{NO}$ about 30 years ago, its field of research has been rapidly expanding and new aspects of NO chemistry and biology continue to emerge. Originally identified as a vasodilator, NO is now known to affect many biological processes of all organisms, from bacteria and single-celled eukaryotes to animals and humans. ${ }^{[14]}$ Endothelium-derived relaxing factor (EDRF) is another name for this pleiotropic molecule which is critical to a number of physiological and pathological processes in humans. It not only inhibits the inflammatory - proliferative reactions in vascular wall cells, but also exerts anti-thrombogenic and endothelial cell protective properties in both autocrine and paracrine fashion. NO initiates and maintains vasodilation through a cascade of biological events that culminate in the relaxation

Table 3: Association of NO levels with age

\begin{tabular}{lccc}
\hline Age, years & \multicolumn{3}{c}{ Total $(\boldsymbol{N = 2 0 8 )}$} \\
\cline { 2 - 4 } & $\boldsymbol{n}$ & $\begin{array}{c}\text { Mean nitric oxide } \\
\text { in serum }(\mu \mathrm{mol} / \mathrm{L})\end{array}$ & SD \\
\hline $41-60$ & 75 & 60.6 & 17.3 \\
$61-80$ & 121 & 58.9 & 18.2 \\
$>80$ & 12 & 59.2 & 15.8 \\
$\mathrm{~F}$ & 0.214 & & \\
$P$ value & 0.807 & & \\
\hline
\end{tabular}

Table 4: Association between the serum NO levels in smoke and non-smoke tobacco usage among diabetes patients

\begin{tabular}{|c|c|c|c|}
\hline \multirow[t]{2}{*}{ Addiction } & \multicolumn{3}{|c|}{ Total $(N=208)$} \\
\hline & $n$ & $\begin{array}{l}\text { Mean nitric oxide } \\
\text { in serum }(\mu \mathrm{mol} / \mathrm{L})\end{array}$ & SD \\
\hline Non-smoker & 168 & 60.60 & 17.89 \\
\hline Smoker & 40 & 54.92 & 16.27 \\
\hline$t$ & 1.833 & & \\
\hline$P$ value & 0.068 & & \\
\hline Tobacco non-users & 138 & 60.61 & 17.05 \\
\hline Tobacco users & 70 & 57.32 & 18.83 \\
\hline$t$ & 1.268 & & \\
\hline$P$ value & 0.206 & & \\
\hline
\end{tabular}


Das, et al.: Smoke and non-smoke tobacco effects on nitric oxide

of smooth muscle cells that line the blood vessels. Unlike other intracellular molecules, it is freely diffusible and influences a number of biosynthetic, metabolic, signaling, and membrane transport processes. ${ }^{[15]}$ It not only dilates the vascular tree, but also inhibits platelet aggregation, thrombus formation, leukocyte adhesion, and vascular proliferation. ${ }^{[16]}$ The concept of smoke tobacco affecting came into being with growing researches on the diverse actions of NO. Higman et al. reported that the release of NO from the saphenous veins of nonsmokers was significantly higher than that from the veins of heavy smokers. ${ }^{[17]}$ Using the NO antagonist, $N^{\mathrm{G}}$-monomethyl-l-arginine, several investigators have found indirect impairment of endothelium-dependent vasodilatation in smokers with decreased NO. ${ }^{[18]}$ In the present study, though we found a near association between tobacco smoke and serum NO levels, in diabetic patients where NO is known to affect the cardiovascular functions, with the additional impact of smoking on NO levels in the body, important deductions could be drawn. But the nicotine in the piece of chewing tobacco is absorbed through the mouth tissues. Whether it causes vascular endothelial dysfunctions is a matter of debate. Our study has shown that it may not affect vascular endothelial functions as the tobacco smoke affects the NO levels of the body. This aspect is important as it may help to formulate strategies and categorize risk assessment.

There were a few limitations of the study. We did not compare the results in normal population, taking them as controls. Also, our sample size was not large and various confounding factors were not excluded from the study.

\section{CONCLUSIONS}

The association between cigarette smoking and vascular diseases is widely recognized, and there is a general consensus that cigarette smoke targets the vascular endothelial cells by its effect on NO. In this study, the difference in associations of different forms of nicotine usage over NO levels was assessed, as it would provide an idea of the mechanism of effects of oral and inhaled forms of nicotine use. In conclusion, new facts have been elucidated in this study, and to the best of our knowledge, it provides the first comparison of smoke and non-smoke tobacco in relation to the serum levels of NO for estimating the burden of vascular risk with various forms of tobacco use.

\section{REFERENCES}

1. Relationship of blood pressure, serum cholesterol, smoking habit, relative weight and ECG abnormalities to incidence of major coronary events: Final report of the pooling project. The Pooling Project Research Group. J Chronic Dis 1978;31:201-306.

2. Jonas MA, Oates JA, Ockene JK, Hennekens CH. Statement on smoking and cardiovascular disease for health care professionals. Circulation 1992;86:1664-9.

3. Strong JP, Richards ML. Cigarette smoking and atherosclerosis in autopsied men. Atherosclerosis 1976;23:451-76.

4. Furchgott RF, Zawadzki JV. The obligatory role of endothelial cells in the relaxation of arterial smooth muscle by acetylcholine. Nature 1980;288:373-6.

5. Palmer RM, Ferrige AG, Moncada S. Nitric oxide release accounts for the biological activity of endothelium-derived relaxing factor. Nature 1987;327:524-6.

6. Elliott TG, Cockcroft JR, Groop PH, Viberti GC, Ritter JM. Inhibition of nitric oxide synthesis in forearm vasculature of insulin-dependent diabetic patients: Blunted vasoconstriction in patients with microalbuminuria. Clin Sci (Lond) 1993;85:687-93.

7. Tesfamariam B, Brown ML, Cohen RA. Elevated glucose impairs endothelium-dependent relaxation by activating protein kinase C. J Clin Invest 1991;87:1643-8.

8. Bohlen HG, Lash JM. Topical hyperglycemia rapidly suppresses EDRF-mediated vasodilation of normal rat arterioles. Am J Physiol 1993;265:H219-25.

9. Hogan M, Cerami A, Bucala R. Advanced glycosylation endproducts block the antiproliferative effect of nitric oxide. Role in the vascular and renal complications of diabetes mellitus. J Clin Invest 1992;90:1110-5.

10. Holbrook JS, Grundy SM, Hennekens CH, Kannel WB, Strong JP. Cigarette smoking and cardiovascular diseases: A statement for health professionals by a task force appointed by the steering committee of the American Heart Association. Circulation 1984;70:1114-7A.

11. Powell JT, Higman DJ. Smoking, nitric oxide and the endothelium. Br J Surg 1994;81:785-7.

12. Chemical constituents and bioactivity of tobacco smoke. In Tobacco, A Major International Health Hazard. In: Zaridge DG, Peto R, editors. International Agency for Research on Cancer, World Health Organization. London: Oxford University Press; 1986p. 145-65.

13. Moncada S, Higgs A. The L-arginine-nitric oxide pathway. N Engl J Med 1993;329:2002-12.

14. Feng $Q$, Scott J. Nitric oxide, from its chemistry to biology and disease. Open Nitric Oxide J 2011;3 (Suppl 1-M1):6-7.

15. Mayer B, Hemmens B. Biosynthesis and action of nitric oxide in mammalian cells. Trends Biochem Sci 1997;22:477-81.

16. Sarkar R, Webb RC. Does nitric oxide regulate smooth muscle cell proliferation? A critical appraisal. J Vasc Res 1998;35:135-42.

17. Higman DJ, Strachan AM, Buttery L, Hicks RC, Springall DR, Greenhalgh RM, et al. Smoking impairs the activity of endothelial nitric oxide synthase in saphenous vein. Arterioscler Thromb Vasc Biol 1996;16:546-52.

18. Kugiyama K, Yasue H, Ohgushi M, Motoyama T, Kawano H, Inobe $Y$, et al. Deficiency in nitric oxide bioactivity in epicardial coronary arteries of cigarette smokers. J Am Coll Cardiol 1996;28:1161-7.

How to cite this article: Das L, Mishra A, Mahdi AA, Singh AS. Effect of smoke and non-smoke tobacco on nitric oxide levels in diabetic patients. J Transl Intern Med 2014;2:36-9.

Source of Support: NIL. Conflict of Interest: None declared 